\title{
Does supplemental external beam radiation therapy impact urinary, bowel, and erectile function following permanent prostate brachytherapy?: results of two prospective randomized trials
}

\author{
Gregory S. Merrick, MD',2, Ava Tennant, BS!, Kent E. Wallner, MD³, Robert Galbreath, PhD',4, Wayne M. Butler, PhD', \\ Ryan Fiano, BS, MPH', Edward Adamovich, MD 5 \\ ISchiffler Cancer Center, Wheeling Jesuit, University Wheeling, WV, ${ }^{2}$ Department of Urology, Wheeling Hospital, Wheeling, WV, ${ }^{3}$ Puget Sound \\ Healthcare Corporation Group, Health Cooperative University of Washington, Seattle, WA, ${ }^{4}$ Ohio University, Eastern St. Clairsville, $\mathrm{OH}$, \\ ${ }^{5}$ Department of Pathology, Wheeling Hospital, Wheeling, WV, USA
}

\begin{abstract}
Purpose: To evaluate the impact of supplemental external beam radiation therapy (EBRT) prior to permanent prostate brachytherapy on long term urinary, bowel, and erectile function.

Material and methods: Patient administered urinary, bowel, and erectile quality of life (QoL) instrument were obtained prior to treatment and following brachytherapy. The study population was comprised of the 457 patients who were alive as of June 2016, had been randomized to two markedly different supplemental EBRT dose regimens and a third arm without supplemental EBRT, and had completed the June 2016 QoL survey. The need for urinary or bowel surgical intervention was prospectively recorded during routine follow-up. Multiple parameters were evaluated for effect on outcomes.

Results: The urinary catheter was removed on day 0 in $92.1 \%$ of patients and $0.4 \%$ required a post-implant transurethral prostatic resection (TURP). On average, the International Prostate Symptom Score (IPSS) normalized at week 14. The 10-year rate of urethral strictures was 5.3\%. No significant differences were discerned between baseline and post-implant rectal function assessment score (RFAS), and no patient developed a rectal ulcer or fistula. The 10-year potency preservation rate was $50.3 \%$. Supplemental EBRT did not affect urinary, bowel, or erectile function. Urethral strictures were most closely related to bulbomembranous urethral brachytherapy doses, post-implant rectal function to pre-implant hemorroidal bleeding, and RFAS and erectile function to pre-brachytherapy international index of erectile function and age.

Conclusions: Supplemental EBRT did not significantly effect catheter dependency, IPSS resolution, urethral stricture rate, the need for post-implant TURP, bowel, or erectile function. Careful attention to brachytherapy dose distributions appears to be most important in minimizing post-brachytherapy morbidity.
\end{abstract}

J Contemp Brachytherapy 2017; 9, 5: 403-409 DOI: https://doi.org/10.5114/jcb.2017.70763

Key words: brachytherapy, morbidity, quality of life, prostate cancer.

\section{Purpose}

Brachytherapy is an efficient treatment modality for potentially curable prostate cancer with the caveat that appropriate patient selection and high quality implant dose distributions are essential for durable local control, favorable biochemical outcomes, and acceptable long-term quality of life $[1,2,3]$. Dose escalation, with brachytherapy either as monotherapy or as a boost following moderate doses of external beam radiation therapy (EBRT), has resulted in marked improvement in biochemical control rates in higher risk patients, compared to dose-escalated EBRT [4]. Although in low-risk patients, brachytherapy is almost always utilized as monotherapy, supplemental EBRT has traditionally been incorporated into intermediate-risk regimens, and is almost always combined with brachytherapy in high-risk patients. However, two recently published prospective randomized trials demonstrated that in patients with a high-risk of extracapsular extension but a low-risk of pelvic lymph node involvement, high quality brachytherapy results in equivalent rates of 
biochemical control with or without supplemental EBRT $[1,5]$. In contrast, the addition of pelvic radiotherapy to brachytherapy in high-risk patients appears to improve biochemical control and cause-specific survival when compared to patients receiving brachytherapy alone [6,7].

In prostate brachytherapy treatment regimens, the impact of supplemental EBRT on long-term urinary, bowel, and sexual function has been studied by multiple investigators with conflicting conclusions [3]. In this study, we evaluated urinary, bowel, and erectile function in patients randomized to two prospective trials via patient administered quality of life (QoL) instruments, and the rate of surgical intervention for urinary and bowel complications.

\section{Material and methods}

From December 1999 to June 2004, 566 patients with clinically organ-confined disease and Gleason scores 7-9 and/or a pre-treatment prostate specific antigen (PSA) $10-20 \mathrm{ng} / \mathrm{ml}$ were randomized to either $20 \mathrm{~Gy}$ of supplemental EBRT in 2 Gy fractions followed by a ${ }^{103} \mathrm{Pd}$ boost (115 Gy), or 44 Gy of supplemental EBRT followed by a $90 \mathrm{~Gy}{ }^{103} \mathrm{Pd}$ boost (44/20 trial). Subsequently, from November 2004 to September 2013, 471 patients with the same inclusion criteria were randomized to either the $20 \mathrm{~Gy}$ arm, or monotherapeutic ${ }^{103} \mathrm{Pd}$ (125 Gy) (20/0 trial). Three hundred and nineteen patients in the $44 / 20$ trial and 88 patients in the 20/0 trial were implanted at the Puget Sound Veterans Administration Hospital, and have been permanently embargoed secondary to administrative (neither ethical nor scientific) institutional review board decisions. As such, the remaining 247 patients in the $44 / 20$ trial and 383 patients in the 20/0 trial (total 630 patients) comprise this evaluation.

All patients in this study underwent implantation by a single brachytherapist (GSM). Prior to implantation, all slides underwent review by a pathologist with significant expertise in prostate pathology (EA). Patients were clinically staged using medical history and physical examination, including digital rectal examination and serum PSA. Bone scans and computed tomography of the abdomen/ pelvis were obtained primarily in patients with Gleason scores $\geq 8$. In all patients, prophylactic $\alpha$-blockers were initiated two weeks prior to implantation and continued until the urinary symptoms resolved.

The brachytherapy planning target volume consisted of the prostate gland with a $5 \mathrm{~mm}$ periprostatic margin and the proximal $1.0 \mathrm{~cm}$ of the seminal vesicles [8,9]. All post-implant dosimetric calculations were based on day 0 dosimetric evaluation. Within two hours of implantation, a computed tomography (CT) scan was obtained, and all dosimetric parameters including prostate and bulbomembranous urethral doses were evaluated from these images. The urethral dose was defined as the geometric center of the urinary catheter on the day 0 CT [10]. The bulbomembranous urethra was defined as being $15 \mathrm{~mm}$ long and beginning at the apex of the prostate gland [11].

Patients receiving supplemental EBRT were treated with a three-dimensional conformal technique using anterior posterior/posterior anterior and opposed lateral portals with $18 \mathrm{MV}$ photons and custom treatment devices to spare as much normal tissue as possible. The target volume consisted of the prostate and seminal vesicles with margin. Patients underwent brachytherapy within 4 days of completing supplemental EBRT in the $20 \mathrm{~Gy}$ arm and 10-14 days in the 44 Gy arm. When prescribed, androgen deprivation therapy (ADT) was initiated 3 months prior to implantation, and consisted of a luteinizing hormone-releasing hormone agonist and an antiandrogen or a luteinizing hormone-releasing hormone antagonist. Androgen deprivation therapy was used for size reduction or secondary to adverse pathologic features.

Prior to consultation, all patients completed the international prostate symptom score (IPSS) [12], the rectal function assessment score (RFAS) [13], and the international index of erectile function-6 (IIEF-6) [14]. Additional evaluations were obtained during follow-up. In June 2016,478 of the 630 patients were alive and were mailed the three QoL instruments with a pre-stamped return envelope. If the questionnaires were not returned within three weeks, additional questionnaires were mailed along with a follow-up call by one of the brachytherapy nurses. Four hundred and 457 patients returned the 2016 questionnaires and comprised the study population (95.6\% response rate). Urinary morbidity was defined by time to IPSS return to baseline \pm 2 points, maximum increase in IPSS, catheter dependency, and the need for post brachytherapy surgical intervention (ie., transurethral resection/transurethral incision). Brachytherapy-related urethral strictures were diagnosed by cystoscopic evaluation. Change in urinary symptoms, decreased urinary stream, substantial IPSS increase, and/or an increase post-void residual urine prompted cystoscopy. The study did not prospectively evaluate dysuria, hematuria, or urinary incontinence. The RFAS instrument consisted of 9 questions, each scored on a 0-3 scale with a range of 0-27 with lower scores indicative of better bowel function [13]. All IIEF questionnaires evaluated erectile function without pharmacologic or mechanical assistance. Men who were potent before therapy, but who reported permanent loss of erectile function immediately after brachytherapy, were assigned a time to erectile dysfunction of 1 day. Otherwise, erectile dysfunction was recorded at the patient's first report. Pre- and post-implant potency was defined as an IIEF $>12$.

Differences in the clinical, treatment, and dosimetric parameters across the 2 groups, for both trials (44/20 and 20/0) in continuous data were determined using a 1-way analysis of variance. When data were categorical, comparisons were used using $\chi^{2}$ analysis. When a cell for a categorical variable contained less than 5 entries, a Fisher's exact test was used. RFAS were compared using a 2-way repeated measure ANOVA, with a between factor of treatment group and a within factor of time. Univariate and multivariate contributors to RFAS, urethral strictures, and erectile function were determined using a Cox regression analysis. IIEF was presented using a Kaplan Meier curve. A comparison of the prevalence of baseline bleeding across treatment groups was determined using a $\chi^{2}$. The time at which post-brachytherapy bleeding ceased was compared across the treatment groups using a Fish- 
er's exact test. For all the tests, $p \leq 0.05$ was considered statistically significant. Statistical analysis was performed using the Statistical Package for Social Sciences, version 18.0 software (SPSS, Inc., Chicago, IL, USA) and STATA 14 (StataCorp LP, College Station, TX, USA).

\section{Results}

Table 1 summarizes the clinical, treatment, and dosimetric parameters of the patients randomized to the $44 / 20$ and 20/0 trials. Of the 630 patients, 478 were alive as of June 2016. Of those 478 patients, 457 returned the June 2016 QoL instruments and comprised the study population. The response rate was $95.6 \%$ and was not significantly different for any of the cohorts. Due to the fact that the trials were conducted sequentially, patients in $44 / 20$ had a significantly longer follow-up than patients in $20 / 0$ $(p \leq 0.001)$. In addition, although there were statistically significant differences in post-implant dosimetry, no clinically relevant differences were noticeable. Patients in the 20/0 had significantly more favorable Gleason scores, lower clinical stage, were less likely to receive ADT, but were more likely to have a serum testosterone in the low to lower third of normal range.

The urinary catheter was removed in 419 of 455 patients $(92.1 \%)$ on the day of implantation. Two patients were catheter-dependent prior to implantation and were excluded from this analysis. Of the $7.9 \%$ of patients who required a urinary catheter beyond the first day, only two patients $(0.4 \%)$ required a urinary catheter for more than 5 days. Two patients (both in the 44/20 trial) required a post-implant transurethral resection at 0.3 years and 1.4 years following implantation. IPSS resolution was defined as a post-implant IPSS of 2 points or less than that of the baseline IPSS. On average, IPSS resolution occurred 14 weeks following implantation. Of the 478 patients, 18 developed a urethral stricture at a mean and median of $5.0 \pm 2.3$ years and 5.1 years, respectively (Figure 1 ). The 5, 10, and 15 year rates of urethral strictures were $2.1 \%, 5.3 \%$, and $5.3 \%$, respectively. All strictures involved the bulbomembranous urethra. Over time, the brachytherapy dose to the bulbomembranous urethra decreased along with a decrease in the incidence of bulbomembranous urethral strictures $(p=0.037)$. Although Figure 1 illustrates that urethral strictures were most common in the $44 \mathrm{~Gy}$ arm, in multivariate analysis, urethral strictures were related only to bulbomembranous urethral dose $(p=0.001)$.

Rectal function was assessed by RFAS. Mean and median baseline RFAS scores of 2.8 and 2.6 were recorded while the mean and median post-implant RFAS scores (as of June 2016) were 3.2 and 3.0. No significant differences were discernible between pre- and post-implant function. Prior to treatment, 59 patients $(12.9 \%)$ reported hemorroidal-like bleeding. Following treatment, 9.2\% of patients reported rectal bleeding with $8.3 \%$ reporting category 1 (blood on the toilet paper once a week), and $0.9 \%$ reporting category 2 (blood on the toilet paper 2-3 times per week). No patient in these two trials required cauterization for rectal bleeding or developed a rectal ulcer or fistula. No significant differences in post-implant bleed- ing were detected between the four evaluated groups. In multivariate analysis, neither supplemental EBRT nor post-implant rectal dose predicted for rectal bleeding (no substantial variation in post-implant brachytherapy rectal doses were noted). In multivariate analysis, rectal bleeding was most closely related to pre-implant hemorroidal bleeding $(p<0.001)$ and the pre-implant RFAS $(p=0.001)$.

Figure 2 illustrates potency preservation rates following brachytherapy. At 5, 10, and 15 years, potency preservation rates for the entire cohort were $52.5 \%, 50.2 \%$, and $50.2 \%$, respectively. When the 4 arms were evaluated separately, supplemental EBRT did not impact potency preservation (Figure 3, $p=0.0833$ ). 10-year potency preservation rates of $57.1 \%, 58.8 \%, 34.3 \%$, and $36.0 \%$ were recorded in the 0 Gy, 20 Gy (vs. 0 Gy), 20 Gy (vs. 44 Gy), and $44 \mathrm{~Gy}$ arms, respectively. However, when combined into $20 / 0$ and $44 / 20$ cohorts, a statistically significant improvement in 10-year potency preservation rate was apparent $(58.1 \%$ vs. $35.0 \%, p=0.025)$. Pre-implant potency strongly predicted for post-implant potency preservation (Figure 4). At 10 years, patients with a baseline IIEF of 24-30, 18-23, and 13-17 had potency preservation rates of $56.4 \%, 39.0 \%$, and $31.6 \%$, respectively $(p<0.001)$. In multi-variate analysis, potency preservation was most closely correlated with pre-implant IIEF $(p<0.001)$ and age $(p=0.001)$.

\section{Discussion}

Brachytherapy represents an efficacious treatment modality for clinically localized prostate cancer with favorable biochemical control rates and acceptable morbidity $[1,2,3]$. It has been demonstrated that the combination of supplemental pelvic EBRT and brachytherapy compared to brachytherapy alone improves biochemical control and/or cause-specific survival in patients with highrisk disease $[4,6,7,15]$. However, in intermediate-risk patients with high quality brachytherapy dose distributions, equivalent biochemical control has been documented with and without EBRT $[1,5]$. However, conflicting results regarding the impact of supplemental EBRT on urinary, bowel, and erectile function in brachytherapy patients has been reported [3].

In the present study, supplemental EBRT did not significantly influence long-term urinary morbidity. Previously, Merrick et al. reported that $88.2 \%$ of patients had the urinary catheter permanently removed on the day of implantation, $0.5 \%$ remained urinary catheter dependent for more than 5 days, and $1.2 \%$ required a post-implant transurethral prostatic resection (TURP) [12]. These results are comparable to the current study, which reports a $0.4 \%$ incidence of urinary catheter dependency beyond 5 days, and a $0.4 \%$ incidence of TURP. In addition, Merrick et al. reported the IPSS returned to baseline at a mean of 13.3 weeks, which is consistent with the 14 weeks reported in this series [12]. In both studies, supplemental EBRT did not influence prolonged IPSS elevation. Multiple additional low-dose-rate (LDR) brachytherapy studies have also concluded that supplemental EBRT does not impact urinary morbidity in terms of IPSS resolution or urinary retention $[16,17,18,19]$. In contrast, high-rose-rate (HDR) 
Table 1. Clinical parameters of the study population, stratified by treatment group

\begin{tabular}{|c|c|c|c|c|c|c|c|c|c|c|c|}
\hline \multirow[t]{2}{*}{ Factor } & \multicolumn{4}{|c|}{44 Gy vs. 20 Gy } & \multicolumn{4}{|c|}{20 Gy vs. 0 Gy } & \multicolumn{3}{|c|}{ Total } \\
\hline & \multicolumn{2}{|c|}{$44 \mathrm{~Gy}$} & \multicolumn{2}{|c|}{$20 \mathrm{~Gy}$} & \multicolumn{2}{|c|}{$20 \mathrm{~Gy}$} & \multicolumn{2}{|c|}{$0 \mathrm{~Gy}$} & & & \\
\hline $\begin{array}{l}\text { Number of randomized } \\
\text { patients }\end{array}$ & \multicolumn{2}{|c|}{125} & \multicolumn{2}{|c|}{122} & \multicolumn{2}{|c|}{196} & \multicolumn{2}{|c|}{187} & \multicolumn{3}{|c|}{630} \\
\hline $\begin{array}{l}\text { Number of patients, } \\
\text { alive }\end{array}$ & \multicolumn{2}{|c|}{68} & \multicolumn{2}{|c|}{69} & \multicolumn{2}{|c|}{177} & \multicolumn{2}{|c|}{164} & \multicolumn{3}{|c|}{478} \\
\hline $\begin{array}{l}\text { Number of patients, } \\
\text { responding }\end{array}$ & \multicolumn{2}{|c|}{65} & \multicolumn{2}{|c|}{65} & \multicolumn{2}{|c|}{167} & 16 & & & 457 & \\
\hline Percent responding & $(95$ & & $(94$ & & $(94$ & & $(97$ & & & $(95.6)$ & \\
\hline Continuous variables & Median & Mean & Median & Mean & Median & Mean & Median & Mean & $p$ & Median & Mean \\
\hline Age at implant (yrs) & 64.0 & 63.2 & 64.0 & 62.8 & 63.0 & 62.8 & 64.0 & 63.8 & 0.5827 & 63.0 & 63.2 \\
\hline Follow-up (yrs) & 14.0 & 14.0 & 14.0 & 13.7 & 6.0 & 6.3 & 7.0 & 6.6 & $<0.001$ & 8.0 & 8.6 \\
\hline PSA & 5.9 & 6.5 & 5.7 & 6.4 & 5.1 & 5.6 & 5.6 & 6.2 & 0.0637 & 5.4 & 6.1 \\
\hline Gleason score & 7.0 & 7.1 & 7.0 & 7.0 & 7.0 & 7.0 & 7.0 & 6.9 & $<0.001$ & 7.0 & 7.0 \\
\hline $\begin{array}{l}\text { Percent positive } \\
\text { biopsies }\end{array}$ & 40.0 & 46.1 & 36.4 & 38.4 & 28.8 & 32.5 & 25.0 & 28.3 & $<0.001$ & 31.6 & 33.8 \\
\hline BMI & 28.6 & 28.7 & 27.3 & 28.0 & 28.7 & 29.5 & 28.5 & 29.2 & 0.1478 & 28.5 & 29.0 \\
\hline Prostate volume & 32.8 & 33.4 & 34.7 & 34.7 & 28.6 & 29.4 & 30.0 & 29.8 & $<0.001$ & 30.4 & 30.9 \\
\hline$\underline{\mathrm{D}_{90}}$ & 129.7 & 130.3 & 123.4 & 123.5 & 121.1 & 121.4 & 117.8 & 118.2 & $<0.001$ & 121.0 & 121.9 \\
\hline$V_{100}$ & 99.3 & 98.9 & 98.3 & 97.7 & 98.3 & 97.9 & 97.8 & 97.2 & $<0.001$ & 98.2 & 97.8 \\
\hline$V_{150}$ & 79.3 & 78.9 & 73.6 & 74.3 & 73.0 & 72.4 & 70.3 & 70.3 & $<0.001$ & 73.0 & 72.9 \\
\hline $\mathrm{V}_{200}$ & 48.5 & 48.3 & 43.3 & 44.1 & 42.7 & 43.1 & 40.4 & 41.3 & $<0.001$ & 42.7 & 43.4 \\
\hline Categorical variables & Count & $(\%)$ & Count & $(\%)$ & Count & $(\%)$ & Count & $(\%)$ & $p$ & Count & $(\%)$ \\
\hline PSA & & & & & & & & & & & \\
\hline$\leq 10$ & 60 & (92.3) & 60 & $(92.3)$ & 159 & $(95.2)$ & 146 & $(91.2)$ & 0.552 & 425 & (93.0) \\
\hline$>10$ & 5 & $(7.7)$ & 5 & $(7.7)$ & 8 & $(4.8)$ & 14 & $(8.8)$ & & 32 & (7.0) \\
\hline Gleason score & & & & & & & & & & & \\
\hline$\leq 6$ & 3 & $(4.6)$ & 3 & $(4.6)$ & 4 & $(2.4)$ & 10 & $(6.3)$ & & 20 & $(4.4)$ \\
\hline $7(3+4)$ & 28 & $(43.1)$ & 36 & $(55.4)$ & 115 & $(68.9)$ & 120 & $(75.0)$ & & 299 & $(65.4)$ \\
\hline $7(4+3)$ & 24 & $(36.9)$ & 20 & $(30.8)$ & 45 & $(27.0)$ & 30 & $(18.8)$ & $<.001$ & 119 & $(26.0)$ \\
\hline 8 & 7 & $(10.8)$ & 5 & $(7.7)$ & 3 & $(1.8)$ & 0 & $(0.0)$ & & 15 & (3.3) \\
\hline 9 & 3 & $(4.6)$ & 1 & $(1.5)$ & 0 & $(0.0)$ & 0 & $(0.0)$ & & 4 & $(0.9)$ \\
\hline Clinical stage $^{\dagger}$ & & & & & & & & & & & \\
\hline$\leq \mathrm{T} 2 \mathrm{a}$ & 61 & $(93.9)$ & 61 & $(93.9)$ & 167 & $(100.0)$ & 155 & $(96.9)$ & & 444 & $(97.2)$ \\
\hline $\mathrm{T} 2 \mathrm{~b}$ & 3 & $(4.6)$ & 4 & $(6.2)$ & 0 & $(0.0)$ & 5 & (3.1) & 0.003 & 12 & $(2.6)$ \\
\hline $\mathrm{T} 2 \mathrm{C}$ & 1 & $(1.5)$ & 0 & $(0.0)$ & 0 & $(0.0)$ & 0 & $(0.0)$ & & 1 & $(0.2)$ \\
\hline $\mathrm{ADT}^{\dagger}$ & & & & & & & & & & & \\
\hline None & 44 & $(67.7)$ & 51 & $(78.5)$ & 153 & $(91.6)$ & 153 & $(95.6)$ & & 401 & $(87.8)$ \\
\hline$\leq 6$ months & 16 & $(24.6)$ & 14 & $(21.5)$ & 13 & $(7.8)$ & 5 & $(3.1)$ & 0.001 & 48 & $(10.5)$ \\
\hline$>6$ months & 5 & $(7.7)$ & 0 & $(0.0)$ & 1 & $(0.6)$ & 2 & $(1.3)$ & & 8 & $(1.8)$ \\
\hline Hypertension & & & & & & & & & & & \\
\hline No & 29 & $(44.6)$ & 37 & $(56.9)$ & 74 & $(44.3)$ & 74 & $(46.3)$ & 0.357 & 214 & $(46.8)$ \\
\hline Yes & 36 & $(55.4)$ & 28 & $(43.1)$ & 93 & $(55.7)$ & 86 & $(53.8)$ & & 243 & $(53.2)$ \\
\hline Diabetes $^{\dagger}$ & & & & & & & & & & & \\
\hline No & 56 & $(86.2)$ & 61 & (93.9) & 144 & $(86.2)$ & 140 & $(87.5)$ & 0.410 & 401 & $(87.8)$ \\
\hline Yes & 9 & $(13.9)$ & 4 & $(6.2)$ & 23 & $(13.8)$ & 20 & $(12.5)$ & & 56 & (12.3) \\
\hline Hypercholesterolemia & & & & & & & & & & & \\
\hline No & 50 & (76.9) & 48 & (73.9) & 86 & $(51.5)$ & 83 & (51.9) & $<0.001$ & 267 & (58.4) \\
\hline Yes & 15 & $(23.1)$ & 17 & $(26.2)$ & 81 & $(48.5)$ & 77 & $(48.1)$ & & 190 & $(41.6)$ \\
\hline
\end{tabular}


Table 1. Cont.

\begin{tabular}{|c|c|c|c|c|c|c|c|c|c|c|c|}
\hline Categorical variables & Count & (\%) & Count & (\%) & Count & (\%) & Count & (\%) & $p$ & Count & (\%) \\
\hline \multicolumn{12}{|l|}{ Cardiovascular disease } \\
\hline No & 57 & $(87.7)$ & 55 & $(84.6)$ & 137 & (82.0) & 140 & $(87.5)$ & \multirow[t]{2}{*}{0.508} & 389 & $(85.1)$ \\
\hline Yes & 8 & $(12.3)$ & 10 & $(15.4)$ & 30 & $(18.0)$ & 20 & $(12.5)$ & & 68 & $(14.9)$ \\
\hline \multicolumn{12}{|l|}{ Tobacco $^{\dagger}$} \\
\hline Never & 24 & (36.9) & 28 & $(43.1)$ & 63 & $(37.7)$ & 65 & $(40.6)$ & \multirow{3}{*}{0.182} & 180 & (39.4) \\
\hline Former & 35 & $(53.9)$ & 33 & $(50.8)$ & 77 & $(46.1)$ & 66 & $(41.3)$ & & 211 & $(46.2)$ \\
\hline Current & 6 & $(9.2)$ & 4 & $(6.2)$ & 27 & $(16.2)$ & 29 & $(18.1)$ & & 66 & (14.4) \\
\hline \multicolumn{12}{|l|}{ Testosterone* } \\
\hline $\begin{array}{l}\text { Low \& lower } 1 / 3 \\
\text { of normal }\end{array}$ & 21 & $(65.6)$ & 18 & $(48.7)$ & 124 & $(75.6)$ & 108 & $(68.8)$ & \multirow{3}{*}{0.007} & 271 & $(69.5)$ \\
\hline Middle $1 / 3$ of normal & 6 & $(18.8)$ & 12 & (32.4) & 33 & $(20.1)$ & 39 & $(24.8)$ & & 90 & (23.1) \\
\hline $\begin{array}{l}\text { Upper } 1 / 3 \text { of normal } \\
\text { \& high }\end{array}$ & 5 & $(15.6)$ & 7 & $(18.9)$ & 7 & $(4.3)$ & 10 & (6.4) & & 29 & (7.4) \\
\hline
\end{tabular}

*67 subjects without testosterone levels

${ }^{\dagger}$ Fisher exact test

PSA - prostate specific antigen, $B M I$ - body mass index, $D_{90}$ - the percentage of the prescribed dose received by $90 \%$ volume of the prostate, $V_{100}, V_{150}, V_{200}-v_{0}$ lume of the anatomic volume receiving 100\%,150\%, 200\% of the prescribed dose, ADT-androgen deprivation therapy
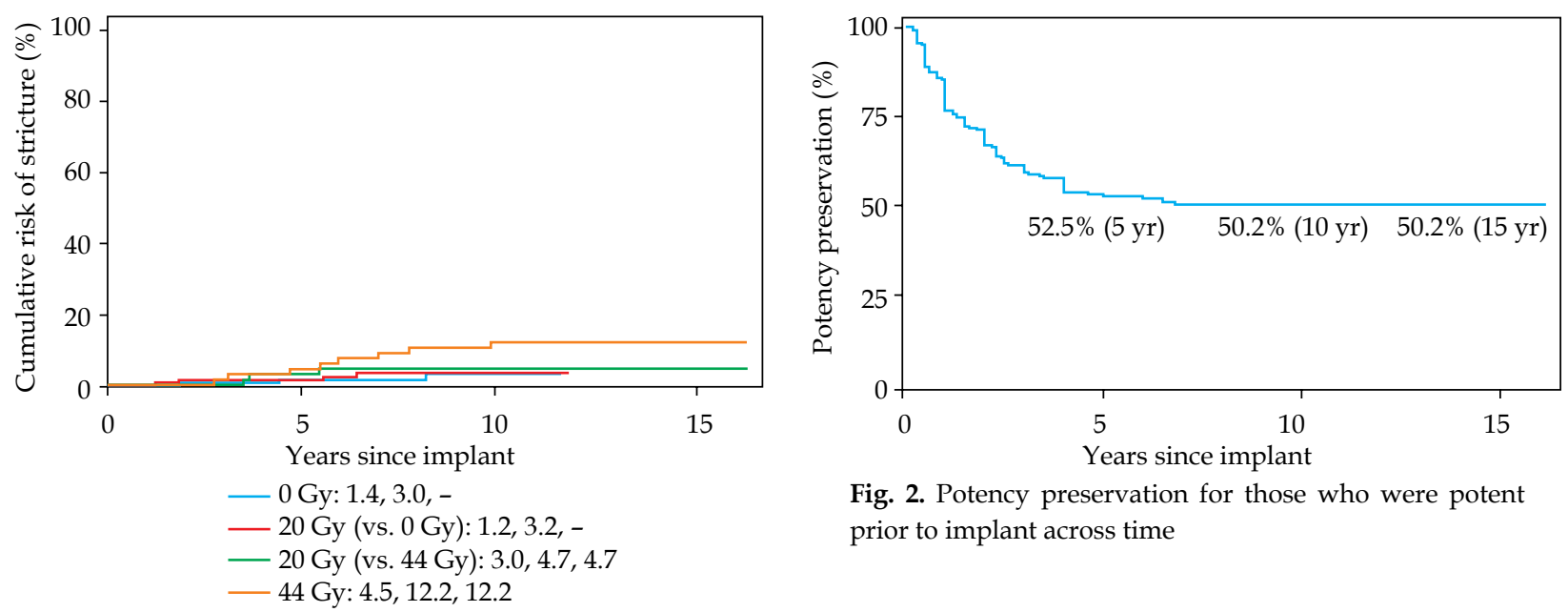

Fig. 2. Potency preservation for those who were potent prior to implant across time

Fig. 1. Cumulative risk of stricture across time (at 5, 10, and 15 years), stratified by treatment group

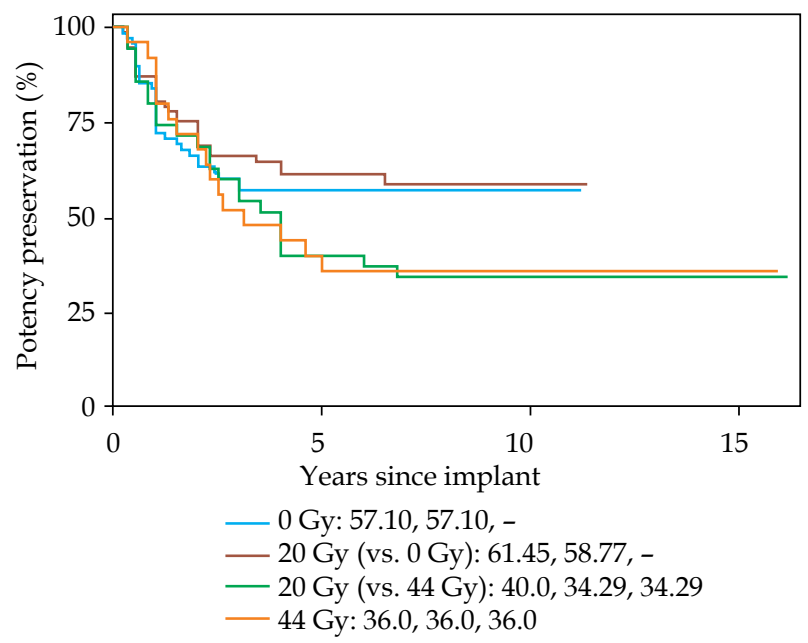

Fig. 3. Potency preservation across time for those who were potent prior to implant, stratified by treatment group

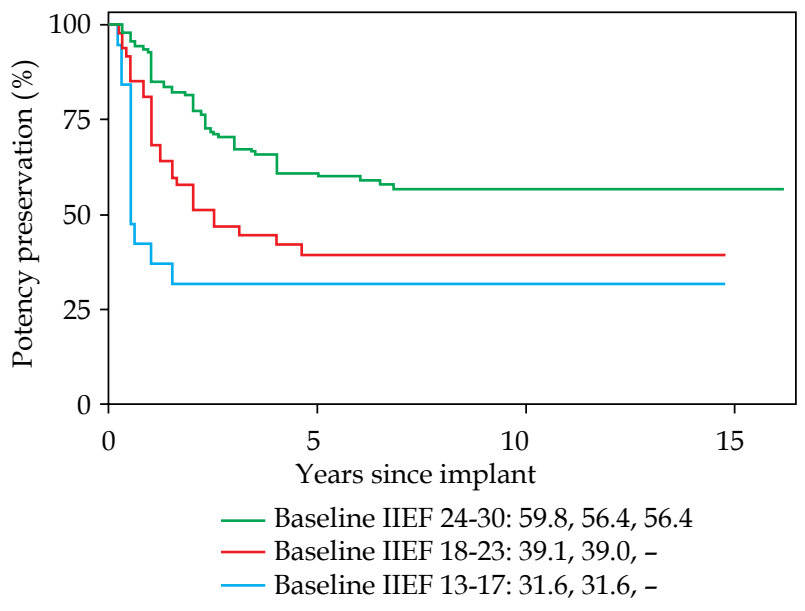

Fig. 4. Potency of baseline-potent patients over time, stratified by IIEF score 
combined with supplemental EBRT appears to increase urinary morbidity [20]. A shortcoming of the current study is that urinary morbidity was evaluated by serial IPSS, which does not include evaluation of incontinence, hematuria, or dysuria. It is possible that supplemental EBRT may have adversely affected these variables.

Previously, in a series of 1,186 patients, a 9-year actuarial risk of bulbomembranous urethral strictures of $3.6 \%$ with a median time to development of 2.4 years was reported [21]. In the current study, a somewhat higher risk of urinary stricture disease was noted (5.3\% at 10 years). Consistent with the previous study, the mean radiation dose to the bulbomembranous urethra was significantly greater in patients with than those without stricture. In the above mentioned study [21], bulbomembranous dose and supplemental EBRT predicted for stricture. In a review of the CaPSURE database, urethral strictures were significantly greater when brachytherapy was combined with supplemental EBRT vs. monotherapeutic brachytherapy (5.2\% vs. $1.8 \%$ ) [22]. In these 2 randomized trials, the brachytherapy dose to the bulbomembranous urethra was most closely related to urethral strictures. It is essential that careful attention should be paid to brachytherapy planning and intraoperative execution in order to limit periapical doses, which will minimize the risk of urethral strictures. Consistent with IPSS resolution [20], it appears that when HDR is combined with supplemental EBRT, the risk of urethral stricture disease is substantially greater. In 2 HDR studies [23,24], the 6 and 2 year rate of urethral strictures were $15.3 \%$ and $8.2 \%$, respectively, with the HDR dose schedule being the only significant predictor of stricture. Following permanent prostate brachytherapy, the bulbomembranous urethral doses should be limited to $<75 \%$ of prescription dose in order to minimize the subsequent risk of strictures. Orio et al. reported favorable long-term rectal function following brachytherapy using the RFAS instrument [13]. The number of pre-implant bowel movements, tobacco, and diabetes correlated with post-implant RFAS. In the Orio series, RFAS scores of 4.29, 3.92, 4.00, and 3.35 were noted in 4 consecutive series published in 1999, 2002, 2006, and 2012. Consistent with those results, the median post-implant RFAS in the current series was 3.0. In the Orio series, supplemental EBRT correlated with the patient's perception of overall rectal quality of life. Unfortunately, in these two prospective randomized trials, patient perception was not part of the questionnaire. In the current study, a 9.2\% incidence of self-limited rectal bleeding was reported. Consistent with these results, Price et al. reported a freedom from grade $\geq 2$ proctitis of $92.8 \%$ for brachytherapy alone, and $93.5 \%$ for patients treated with brachytherapy and supplemental EBRT [25]. In 870 intermediate-risk prostate cancer patients treated with either IMRT (86.4 Gy) or supplemental EBRT plus brachytherapy, grade 2 GI toxicity rates of $4.6 \%$ vs. $4.1 \%$ were noted for IMRT (intensity-modulated radiotherapy) vs. supplemental EBRT plus brachytherapy $(p=0.89)$ [26]. In contrast to these findings, Brandeis et al. reported a greater incidence of rectal complications when supplemental EBRT was added to brachytherapy [27]. In addi- tion, prevention of constipation is essential to limit rectal dose and decrease possible complications [28].

Retrospective studies have demonstrated that combination therapy results in higher rates of erectile dysfunction in prostate brachytherapy patients. However, recent studies to include a series that evaluated erectile function in patients treated with IMRT vs. supplemental EBRT plus brachytherapy, reported no difference in erectile preservation $(57.8 \%$ with IMRT and $55.0 \%$ in the combination arm, $p=0.67$ ) [26]. Previously, Merrick et al. reported a dramatic decrease in erectile dysfunction when dose to the penile bulb was minimized [29,30]. Additional contemporary series also reported no difference in erectile dysfunction at 5 years following dose-escalated EBRT compared to combination therapy when vessel sparing radiation was employed [31,32]. In the current study, marked improvement in erectile dysfunction was noted when the $20 / 0$ trial was compared to the $44 / 20$ trial $(58.1 \%$ vs. $35.0 \%$ at 10 years, $p=0.025)$. The randomized trials did not evaluate dose to the proximal penis, but it is likely that the improvement of erectile function over time (since the 2 trials were conducted sequentially) is due to decreased brachytherapy doses to the proximal penis as we have previously documented [29,30]. Previously, we reported that with decreased doses to the proximal penis potency preservation rates increased from 39\% (2005) to $52 \%(2009)[29,30]$. Taken together, these series suggest that dose restriction to critical adjacent structures is essential to improve erectile dysfunction. Buckstein et al. reported that in multivariate analysis only age influenced post-implant erectile function [33]. In our current study, age and pre-implant erectile dysfunction were the best predictors for erectile dysfunction.

Shortcomings of our study include that all patients were treated at a single institution and by a single brachytherapist. In addition, ADT was administered without protocol guidelines and as such its role in the morbidity of these patients cannot be clearly determined.

\section{Conclusions}

Within the confines of the dose and target volume of supplemental EBRT utilized in these two prospective randomized trials, the addition of supplemental EBRT did not significantly effect catheter dependency, IPSS resolution, urethral stricture rate, the need for post-implant TURP, bowel, or erectile function. Careful attention to brachytherapy dose distributions appears to be most important in minimizing post-brachytherapy morbidity.

\section{Disclosure}

Authors report no conflict of interest.

\section{References}

1. Merrick GS, Wallner KE, Galbreath RW et al. Is supplemental external beam radiation therapy necessary for patients with higher risk prostate cancer treated with 103Pd? Results of two prospective randomized trials. Brachytherapy 2015; 14: 677-685.

2. Stone NN, Stock RG, Cesaretti JA et al. Local control following permanent prostate brachytherapy: Effect of high bio- 
logically effective dose on biopsy results and oncologic outcomes. Int J Radiat Oncol Biol Phys 2010; 76: 355-360.

3. Spratt DE, Soni PD, McLaughlin PW et al. The American Brachytherapy Society Task Group Report: Combination of brachytherapy and external beam radiation for high-risk prostate cancer. Brachytherapy 2017; 16: 1-12.

4. Morris WJ, Tyldesley S, Paki HH et al. ASCENDE-RT: A multicenter, randomized trial of dose-escalated external beam radiation therapy (EBRT-B) versus low-dose-rate brachtyerhapy (LDR-B) for men with unfavorable-risk localized prostate cancer. J Clin Oncol 2015; 33 Suppl 7: abstr 3.

5. Merrick GS, Wallner KE, Galbreath RW et al. Is supplemental external beam radiation therapy essential to maximize brachytherapy outcomes in patients with unfavorable intermediate-risk disease? Brachytherapy 2016; 15: 79-84.

6. Shilkrut M, McLaughlin PW, Merrick GS et al. Treatment Outcomes in Very High-risk Prostate Cancer Treated by Dose-escalated and Combined-Modality Radiation Therapy. Am J Clin Oncol 2016; 39: 181-188.

7. Nepple KG, Stephenson AJ, Kallogjeri D et al. Mortality after prostate cancer treatment with radical prostatectomy, external-beam radiation therapy, or brachytherapy in men without comorbidity. Eur Urol 2013; 64: 372-378.

8. Merrick GS, Butler WM. Modified uniform seed loading for prostate brachytherapy: Rationale, design, and evaluation. Tech Urol 2000; 6: 78-84.

9. Merrick GS, Butler WM, Wallner KE et al. Dosimetry of an extracapsular annulus following permanent prostate brachytherapy. Am J Clin Oncol 2007; 30: 228-233.

10. Butler WM, Merrick GS, Dorsey AT et al. Comparison of dose length, area, and volume histograms as qualifies of urethral dose in prosate brachytherapy. Int J Radiat Oncol Biol Phys 2000; 48: 1575-1582.

11. Jordan GH, Schlossberg SM, Devine CJ. Surgery of the penis and urethra. In: Campbell's Urology. $7^{\text {th }}$ ed. Walsh PC, Retik AB, Vaughan ED Jr, Wein AJ (eds.). WB Sauders Co, Philadelphia 1998; vol. 3, sect. XIV, chapt. 107, p. 3401.

12. Merrick GS, Butler WM, Lief JH et al. Temporal resolution of urinary morbidity following prostate brachytherapy. Int J Radiat Oncol Biol Phys 2000; 47: 121-128.

13. Orio PF 3rd, Merrick GS, Galbreath RW et al. Patient-reported long-term rectal function after permanent interstitial brachytherapy for clinically localized prostate cancer. Brachytherapy 2012; 11: 341-347.

14. Taira AV, Merrick GS, Galbreath RW et al. Erectile function durability following permanent prostate brachytherapy. Int J Radiat Oncol Biol Phys 2009; 75: 639-648.

15. Morris, WJ, Tyldesley S, Rodda S et al. Androgen suppression combined with elective nodal and dose escalated radiation therapy (the ASCENDE-RT Trial): An analysis of survival endpoints for randomized trials comparing a lowdose-rate brachytherapy boost to a dose-escalated external beam boost for high- and intermediate-risk prostate cancer. Int J Radiat Oncol Biol Phys 2017; 98: 275-285.

16. Buckstein M, Carpenter TJ, Stone NN et al. Long-term outcomes and toxicity in patients treated with brachytherapy for prostate adenocarcinoma younger than 60 years of age at treatment with minimum 10 years of follow-up. Urology 2013; 81: 364-368

17. Stone NN, Gerber NK, Blacksburg $S$ et al. Factors influencing urinary symptoms 10 years after permanent prostate seed implantation. J Urol 2012; 187: 117-123.

18. Eriguchi T, Yorozu A, Kuroiwa $\mathrm{N}$ et al. Predictive factors for urinary toxicity after iodine-125 prostate brachytherapy with or without supplemental external beam radiotherapy. Brachytherapy 2016; 15: 288-295.
19. Li X, Fang D, Cooperberg MR et al. Long-term follow-up of international prostate symptom score (IPSS) in men following prostate brachytherapy. World J Urol 2014; 32: 1061-1066.

20. Tward JD, Jarosek S, Chu H et al. Time Course and Accumulated Risk of Severe Urinary Adverse Events After HighVersus Low-Dose-Rate Prostate Brachytherapy With or Without External Beam Radiation Therapy. Int J Radiat Oncol Biol Phys 2016; 95: 1443-1453.

21. Merrick GS, Butler WM, Wallner KE et al. Risk factors for the development of prostate brachytherapy related urethral strictures. J Urol 2006; 175: 1376-1381.

22. Elliott SP, Meng MV, Elkin EP et al. CaPSURE Investigators. Incidence of urethral stricture after primary treatment for prostate cancer: data From CaPSURE. J Urol 2007; 178: 529-534.

23. Bece A, Patanjali N, Jackson M et al. High-dose-rate brachytherapy boost for prostate cancer: Outcomes and genitourinary toxicity. Brachytherapy 2015; 14: 670-676.

24. Hindson BR, Millar JL, Matheson B. Urethral strictures following high-dose-rate brachytherapy for prostate cancer: analysis of risk factors. Brachytherapy 2013; 12: 50-55.

25. Price JG, Stone NN, Stock RG. Predictive factors and management of rectal bleeding side effects following prostate cancer brachytherapy. Int J Radiat Oncol Biol Phys 2013; 86: 842-847.

26. Spratt DE, Zumsteg ZS, Ghadjar P et al. Comparison of highdose (86.4 Gy) IMRT vs. combined brachytherapy plus IMRT for intermediate-risk prostate cancer. BJU Int 2014; 114: 360-367.

27. Brandeis JM, Litwin MS, Burnison CM et al. Quality of life outcomes after brachytherapy for early stage prostate cancer. J Urol 2000; 163: 851-857.

28. Otón LF, Dolado MC, Núñez EJ et al. Effect of constipation on dosimetry after permanent seed brachytherapy for prostate cancer. J Contemp Brachytherapy 2015; 7: 247-251.

29. Merrick GS, Butler WM, Wallner KE et al. Erectile function after prostate brachytherapy. Int J Radiat Oncol Biol Phys 2005; 62: 437-447.

30. Taira AV, Merrick GS, Galbreath RW et al. Erectile function durability following permanent prostate brachytherapy. Int J Radiat Oncol Biol Phys 2009; 75: 639-648.

31. McLaughlin PW, Narayana V, Meirovitz A et al. Vessel-sparing prostate radiotherapy: Dose limitation to critical erectile vascular structures (internal pudendal artery and corpus cavernosum) defined by MRI. Int J Radiat Oncol Biol Phys 2005; 61: 20-31

32. Lee JY, Spratt DE, Liss AL et al. Vessel-sparing radiation and functional anatomy-based preservation for erectile function after prostate radiotherapy. Lancet Oncol 2016; 17: e198-e208.

33. Buckstein M, Kerns S, Forysthe K et al. Temporal patterns of selected late toxicities in patients treated with brachytherapy or brachytherapy plus external beam radiation for prostate adenocarcinoma. BJU Int 2013; 111 (3Pt B): E43-E47. 